\title{
The inheritance of seed dormancy in Sinapis arvensis $\mathrm{L}$.
}

\author{
K. Garbutt* and J. R. Witcombe $\dagger$
}

School of Plant Biology, University College of North Wales, Bangor, Gwynedd, U.K.

Selection for dormant and non-dormant seed in Sinapis arvensis was carried to the seventh and fourteenth generation, respectively. Crosses between the dormant and non-dormant lines clearly showed both a maternal and an embryonic component of seed dormancy. A model for the number of alleles controlling dormancy was constructed and tested. The maternal component of dormancy was shown to be controlled by a single locus with two alleles, the dormant allele being dominant to the non-dormant. No clear picture of the control of the embryonic component of dormancy was found.

\section{INTRODUCTION}

There have been several reports of genetic control of factors affecting seed dormancy in plants. Honing (1930) showed a genetic basis and a distinct maternal effect in the light dependence of germination behaviour, in tobacco. Harper and McNaughton (1960) found evidence of genetic control of seed dormancy in species of Papaver. New $(1958 ; 1959 ; 1961)$ has shown a strict genetic control of seed coat types associated with differing germination rates in Spergula arvensis indicating a strict maternal control, via the seed coat, over seed dormancy.

Naylor and his co-workers have shown genetic variability in seed dormancy in Avena fatua in response to several environmental variables applied both whilst the seed is maturing and during germination tests (Naylor and Jana, 1976; Naylor and Fedec, 1978; Sawhney and Naylor, 1979). Jain (1982) has also demonstrated genetic components of seed dormancy for Arena barbata and Trifolium hirtum but in the same study was unable to demonstrate a significant genetic component of dormancy in Bromus mollis.

Hilu and de Wet (1980) have investigated the genetic basis of dormancy in Eleusine sp. and have

Present addresses: * The Biological Laboratories, Harvard University, 16 Divinity Avenue, Cambridge, MA 02138. † ICRISAT, Pantancheru P.O., Andhra Pradesh 502324 India. shown a clear response to selection for nondormancy in several populations. They also demonstrated a clear difference in germinability between threshed and unthreshed grains, indicating the presence of inhibitors in the lemma and palea, and hence a maternal component to control of dormancy.

There have been two recent attempts to estimate the number of loci involved in the control of germination. Guenther and Borriss (1975) tried unsuccessfully to estimate the number of loci controlling seed dormancy in Antirrhinum spp. concluding that dormancy was controlled by a polygenic complex. However, Jana, Acharya and Naylor (1979) have shown that at least three loci control after-ripening in Avena fatua.

In the field, Sinapis arvensis populations usually show two "flushes" of germination each year, one in spring and the other in autumn. Edwards (1980) suggests that the autumnal population results from the non-dormant fraction of the seed produced in the spring. In the field, $S$. arvensis germination is controlled to some extent by environmental factors. Edwards (1980) found germination to be associated with soil temperatures of $4.4^{\circ} \mathrm{C}$ at a depth of $10 \mathrm{~cm}$ and with high rainfall in spring and simply with adequate moisture in autumn. There is also evidence that at least some seed of $S$. arvensis require light to germinate (Frankland, 1976). In the laboratory, dormancy is broken by the application of gibberellic acid 
(Witcombe and Whittington, 1972; Edwards, 1976).

The presence of a germination inhibitor and its mode of action in seeds of $S$. arvensis was reported in Edwards (1968c). This inhibitor is apparently produced by the seed coat (testa) (Witcombe, Hillman and Whittington, 1969) and seems to be present in the seed coat of all seeds in apparently similar quantities (see Edwards, 1968 $a$ for a detailed description of seed anatomy). The inhibition is broken down by oxidation (Edwards, 1969) and the effect of the seed coat in dormant seed appears to be to prevent this oxidation taking place by being impermeable to oxygen (Edwards, $1968 b$ ). The seed coat is clearly of maternal origin and hence control of dormancy is maternal. There is evidence, however, of a further level of dormancy control, possibly unrelated to this maternal effect, and located in the embryo (Edwards, 1968c; Witcombe, 1971). This points to one of the major problems in studies of the inheritance of seed dormancy. The seed combines parts of three distinct generations (and genotypes)-the seed coat (maternal), the endosperm (filial but with one paternal and a variable number of maternal genomes) and the embryo (filial). In the ripe seed of Cruciferae, however, the endosperm has disappeared leaving a seed composed of two generations of tissue, seed coat and embryo.

The purpose of the following investigation was to determine the manner in which dormancy was controlled genetically in Sinapis arvensis.

\section{MATERIALS AND METHODS}

In order to establish the genetic basis of seed dormancy, two selection lines, one for dormancy (D) and one for non-dormancy (N.D.), were established from a natural population collected in Nottinghamshire by J. R. Witcombe (Witcombe and Whittington 1972). These lines were taken to the S10 generation for the N.D. line and the S5 generation for the D line by J. R. Witcombe and K. Daniels. The present authors continued selection using the same methods as Witcombe and Whittington (1972) and Witcombe (1971) to the S14 generation for the N.D. line and S7 generation for the D line. At this point, 200 reciprocal pairs of crosses were made between the lines and seed produced to the third filial generation.

As mentioned in the Introduction, the seed is made up of two distinct generations. Thus a special notation will be used. The seed which produces the parent plants has a seed coat of generation $P_{-1}^{s}$ and embryo of generation $P^{e}$, and the plants grown from this seed will be generation $P^{e}$. Seed from a cross between two plants of $P^{e}$ generation will have $P^{s}$ generation seed coat and $F_{1}^{e}$ generation embryo.

All plants were grown in a greenhouse in $10 \mathrm{~cm}$ plastic pots filled with John Innes No. 1 compost. Supplementary light to give a daylength of 16 hours minimum was provided by mercury vapour lamps and temperature was maintained at a minimum of $18^{\circ} \mathrm{C}$. Treatments of fungicide and insecticide were applied as necessary.

All pollinations were made in the same manner whether within or between lines. Dehiscing anthers were removed from the male parent and placed in a watch glass; a flower bud about to open, but not yet showing the stigmatic surface was opened, and emasculated and the newly exposed stigmatic surface loaded with pollen from the anthers of the male parent. The pedicel was marked with paint and 24 hours later a further application of pollen was made.

These crosses produced $P^{s} F_{1}^{e}$ generation seed, 200 individuals of which were grown on and allowed to cross at random to produce $F_{1}^{s} F_{2}^{e}$ generation and seed 200 individuals of which, when grown on and crossed, produced $F_{2}^{s} F_{3}^{e}$ seed.

A further set of crosses was made between $P^{e}$ plants. These comprised 50 crosses between dormant males and females, 50 crosses between nondormant males and females, and 50 crosses between dormant males and non-dormant females. This was to confirm that the differences observed between the germination rates of seed from nondormant maternal parents from the $P_{-1}^{s} P^{e}$ and the $P^{s} F_{1}^{e}$ generations were, in fact, real and not a function of a random difference between generations.

At each generation, $P_{-1}^{s} P^{e}, P^{s} F_{1}^{e}, F_{1}^{s} F_{2}^{e}, F_{2}^{s} F_{3}^{e}$, germination tests were carried out on the seed in closed petri dishes each containing one sheet of $9.0 \mathrm{~cm}$ filter paper. Initially each dish received $5 \mathrm{ml}$ of distilled water. Thereafter, all dishes received distilled water as necessary. The germination tests were carried out at $25^{\circ} \mathrm{C}$, with 24 hour light. The lids of the petri dishes were lifted daily to prevent the build-up of gases which might inhibit germination. Each dish contained 10 seeds unless otherwise stated.

At the conclusion of each test (14 days), the seeds that remained ungerminated were treated with high levels of G.A. (up to $3000 \mu \mathrm{g} /$ litre) to stimulate dormant seeds into germination and thereby detect non-viable seed. Gibberellic acid 
was applied in an aqueous solution at $\mathrm{pH} 7$. All G.A. solutions were made up freshly before an experiment and were used immediately.

With the exception of $F_{2}^{s} F_{3}^{e}$ bulk germination tests were performed (no record of individual plant performance being kept). The results of the bulk tests were based upon as many seeds as possible (between 1000 and 2000 seeds) with only a small sample being kept in reserve. Confidence intervals were obtained using tables from Rohlf and Sokal (1981), when more than 1000 seeds were used the limits for a sample of 1000 were used as a conservative estimate. Tests of $F_{2}^{s} F_{3}^{e}$ seed were based on individual plants, five petri dishes of 20 seeds being set up for each of $100 F_{1}^{s} F_{2}^{e}$ plants. All these tests were carried out under standard conditions as previously described and in distilled water.

\section{RESULTS AND MODEL}

Selection was continued in the N.D. line to generation S14 and in the D line to S7. The response to selection in the $\mathrm{D}$ line is not as obvious as that in the N.D. line and initially a rise in germination rate was observed (fig. 1); this may be due to the release of concealed variation during the first stages of selection. The non-dormant line appeared to respond sharply to selection up to generation $\mathrm{S} 7$ and then tended to reach a plateau, though with a continued slight increase in germination and decline in standard error (calculated from arcsine transformation) between $\mathrm{S} 7$ and $\mathrm{S} 14$ (fig. 1).

Table 1 gives the mean percentage germination and 95 per cent confidence limits for the two lines at the last generation of selection and the control population. The N.D. line is clearly different from the others. The difference between the control and the $\mathrm{D}$ line is small $(0.05>p>0.01)$ from a $t$-test on arcsine transformed data.

Neither 100 per cent germination in the absence of G.A., nor 0 per cent germination could be obtained from the selection lines. Heritability for dormancy had been found by Witcombe (1971) to be approximately 20 per cent, so this failure has been attributed to environmental factors such as the position of the micropyle during germination, or damaged seed coat.

The differences observed (table 2) in the germination behaviour of seed derived from different maternal parents in lines which are expected to have the same embryo genotype ( $F_{1}^{e}$ generation) indicates that some part of the seed other than the embryo has a profound effect upon germination behaviour.

The work of Edwards (1968b) and Witcombe, Hillman and Whittington (1969) indicate that it is

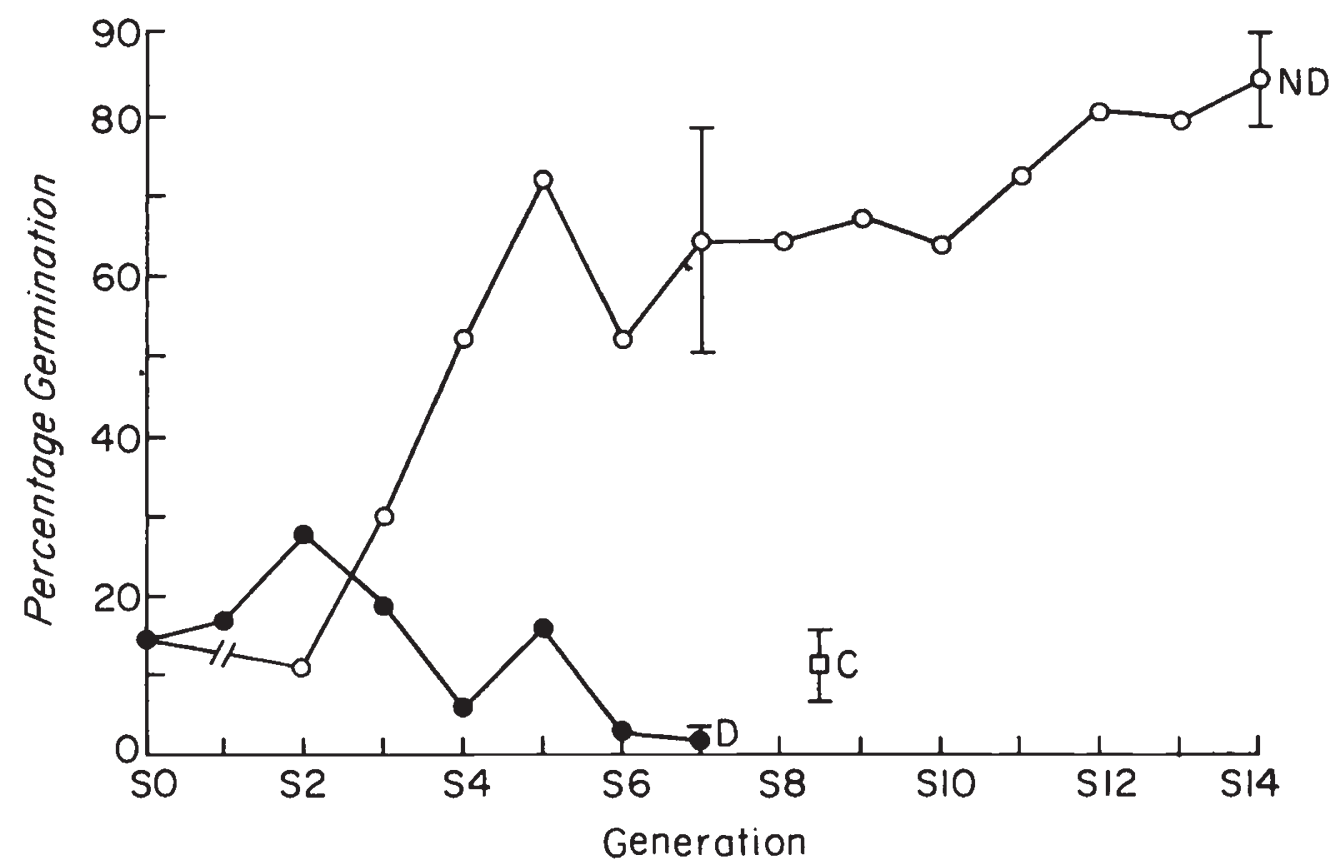

Figure 1 The mean percentage germination of 14 generations of selection for non-dormant seed $(O)$, seven generations for dormant seed (O), and of the unselected control population ( $\square$ ). Bars indicate two Standard Errors. 
Table 1 The mean percentage germination and 95 per cent confidence interval for the non-dormant (N.D.) and dormant (D) selection lines and the unselected control population of Sinapis arvensis

\begin{tabular}{llcc}
\hline Population & Generation & \multicolumn{2}{l}{$\begin{array}{l}\text { Mean percentage } \\
\text { germination }\end{array}$} \\
\hline & & & $\mathrm{L}$ U \\
N.D. & S14 & 84 & $82-86$ \\
D & S7 & 1 & $1-3$ \\
Control & S0 & 11 & $7-15$ \\
\hline
\end{tabular}

Table 2 The seed generations with their maternal phenotype (where known) and mean germination percentage (with 95 per cent confidence interval) resulting from the N.D. $\times D$ cross

\begin{tabular}{llcc}
\hline $\begin{array}{l}\text { Seed } \\
\text { generation }\end{array}$ & $\begin{array}{l}\text { Maternal } \\
\text { phenotype }\end{array}$ & $\begin{array}{l}\text { Mean \% } \\
\text { germination }\end{array}$ \\
\hline & & & $\mathrm{L}$ U \\
$P_{-1}^{s} P^{e}$ & Dormant & 2 & $1-3$ \\
$P_{-1}^{s} P^{e}$ & Non-dormant & 84 & $82-86$ \\
$P^{s} F_{1}^{e}$ & Dormant & 7 & $6-9$ \\
$P^{s} F_{1}^{e}$ & Non-dormant & 58 & $55-62$ \\
$F_{1}^{s} F_{2}^{e}$ & - & 15 & $13-17$ \\
\hline
\end{tabular}

the seed coat rather than the endosperm which is the important factor. As the testa is derived from maternal material the results obtained are at least, in part, a function of the maternal genotype.

The results obtained for $P^{s} F_{1}^{e}$ seed show that an embryo effect is present as well as a maternal effect (table 2). In the case of seed with an N.D. maternal parent, there was a significant difference between the germination precentage of the parents $P_{-1}^{s} P^{e}$ generation and the offspring $P^{s} F_{1}^{e}$ generation. If the only factors affecting germination were maternal, these germination percentages should have been the same.

To confirm this result, a further set of crosses between and within dormant and non-dormant lines was set up (see Materials and Methods). The results of these crosses are given in table 3 . The

Table 3 The germination percentages and their 95 per cent confidence intervals of seed resulting from within and between line crosses of the N.D. and D lines

\begin{tabular}{llrr}
\hline Female parent & Male parent & \multicolumn{2}{c}{ Seed mean $\%$ germination } \\
\hline & & & $\mathrm{L}$ U \\
Dormant & Dormant & 8 & $6-11$ \\
Non-dormant & Non-dormant & 79 & $75-82$ \\
Non-dormant & Dormant & 53 & $49-57$ \\
\hline
\end{tabular}

differences between the seed derived from the N.D. $\times$ N.D. cross and seed from the Female N.D. $\times$ Male D cross (significant at $p<0.02$ ) clearly indicate the effect of the embryo genotype upon germination behaviour.

The results of germination tests upon the $F_{1}^{s} F_{2}^{e}$ generation seem (table 2) to indicate that when the seed coat is heterozygous, as it should be in this generation, the effect of the dormant parent is dominant and the germination is slightly influenced by the embryo genotype.

\section{Model}

From the results in this section, we know that the seed coat, and hence the maternal genotype, has an effect upon seed dormancy. It has also been demonstrated that the embryo genotype, at least when associated with a non-dormant seed coat, has an effect upon dormancy. In the light of these results a working model is suggested where two loci, each with two allelic genes control dormancy. One locus controls that character of the seed coat which inhibits germination with alleles $I$ (inhibiting germination) and allele $i$ (not inhibiting germination). $I$ is considered dominant to $i$. A second locus affects embryo dormancy, the allele $D$ causing embryonic dormancy and $d$ not causing embryonic dormancy. No dominance effect is postulated at this locus. Although it is probable that the control of dormancy in the embryo is more complex than this model would suggest, no clear predictions could be made about the embryonic component so we chose this model for reasons of notational simplicity and parsimony. Given the two parental lines were homozygous, we can now produce genotypes for each generation of crossing (table 4).

If we assume, as seems reasonable, that the effect of $I$ is dominant and only slightly modified by the effect of embryo genes $(D d)$ while $i i$ is altered more by embryo genes, the overall percentage germination of $F_{2}^{s} F_{3}^{e}$ seed will be an almost meaningless value. However, it is predicted that seed coat genotypes $I I, I i$ and $i i$ will be in the ratio of $1: 2: 1$, and if $I$ is dominant it is expected the 75 per cent of the $F_{2}^{e}$ generation plants will produce phenotypically dormant seed and 25 per cent phenotpyically non-dormant seed.

In the recording of results of the germination test on $F_{2}^{s} F_{s}^{e}$ seed, all plants which produced seed which had a germination percentage over 40 per cent were deemed to be phenotypically nondormant and the seed coat assumed to have seed coat genotype $i i$, based on the results of the $P^{s} F_{1}^{e}$, germination tests. 
Table 4 The seed genotypes that it is suggested occur in the $P_{-1}^{s} P^{e}, P^{s} F_{1}^{e}$ and $F_{1}^{s} F_{2}^{e}$ seed generation

\begin{tabular}{|c|c|c|c|}
\hline $\begin{array}{l}\text { Seed } \\
\text { generation }\end{array}$ & $\begin{array}{l}\text { Maternal } \\
\text { phenotype }\end{array}$ & $\begin{array}{l}\% \\
\text { Germination }\end{array}$ & Genotypes \\
\hline \multirow[t]{6}{*}{$P_{-1}^{s} P^{e}$} & Non-dormant & 84 & Seed coat $\overline{i \bar{i}}$ \\
\hline & & & Embryo $\overline{i i}$ \\
\hline & & & $d d$ \\
\hline & Dormant & 2 & Seed coat $\overline{I I}$ \\
\hline & & & Embryo $\overline{I I}$ \\
\hline & & & $\underline{D D}$ \\
\hline \multirow[t]{6}{*}{$P^{s} F_{1}^{e}$} & Non-dormant & 58 & Seed coat $\overline{i i}$ \\
\hline & & & Embryo $\overline{I i}$ \\
\hline & & & $\underline{D d}$ \\
\hline & Dormant & 7 & Seed coat $\overline{I I}$ \\
\hline & & & Embryo $\overline{I i}$ \\
\hline & & & $\underline{D d}$ \\
\hline$F_{1}^{s} F_{2}^{e}$ & - & 15 & \\
\hline
\end{tabular}

$\overline{I i} \underline{I i} \underline{I i} \frac{I i}{I i} \underline{I i} \frac{I i}{I i} \frac{\overline{I i}}{I I I I I I I i \text { Ii Ii i i i i }}$
$\underline{D D} \underline{D d} \underline{d d} \underline{D D} \underline{D d} \underline{d d} \underline{D D} \underline{D d} \underline{d d}$

As a result of germination tests on the $F_{2}^{s} F_{3}^{e}$ seed of 100 plants, 21 plants were found to be phenotypically non-dormant compared with an expectation of 25 non-dormant plants $\left(\chi_{1}^{2}=\right.$ 0.853 N.S.). Thus the $F_{2}^{s} F_{3}^{e}$ seed behaves as predicted by the model.

Figure 2 shows the divergence of the dormanttype and non-dormant-type plants in the $F_{2}^{e}$ generation. The range of variation shown by the non-dormant plants may indicate that the embryonic component is more complex than the model suggests. However, environmental factors can and do affect germination rates and as, at present, it is not possible to distinguish between these effects the model is retained for reasons of parsimony.

\section{DISCUSSION}

This model is a working base from which to proceed. From the various tests and the rate at which the non-dormant line responded to selection, it seems clear that the action of the seed coat in inhibiting germination is under major gene control. The expression of seed coat dormancy is modified, particularly in the case of the recessive allele, by the alleles present in the embryo.

The number of the genes expressed by the embryo is not clear from this work and the single locus two allele system proposed, while plausible, was used for convenience of notation rather than from any feeling that it is necessarily correct. Further investigations are necessary to identify the true nature of the genetic control of dormancy in the embryo. What has emerged clearly from this work is the overriding importance of the maternal genotype in seed dormancy and that at least two gene loci control dormancy in $S$. arvensis.

There have been several mathematical and computer models of seed banks and their effects upon fitness (e.g., Cohen, 1966; Charlesworth, 1974; Templeton and Levin, 1979). It seems to be agreed that one of the most important functions of the seed bank is to reduce the fitness uncertainty produced by cyclical and random environments and thus prevent the "tracking" of temporary adaptive optima. However, dormancy itself may be affected by selection (as has been demonstrated here) and is not necessarily protected from random environmental variations in the way that dormancy protects other characters. The effect of a maternal influence in the dormancy phenotype of seed will be to dampen the tendency to "track" environmental change, in much the same way as the seed bank itself dampens the response of a population. This may help to explain the success of $S$. arvensis as an agricultural weed and its survival under a number of cultivation regimes. Edwards (1980) showed that plants which germinate in the autumn are prevented from reproducing by autumn 


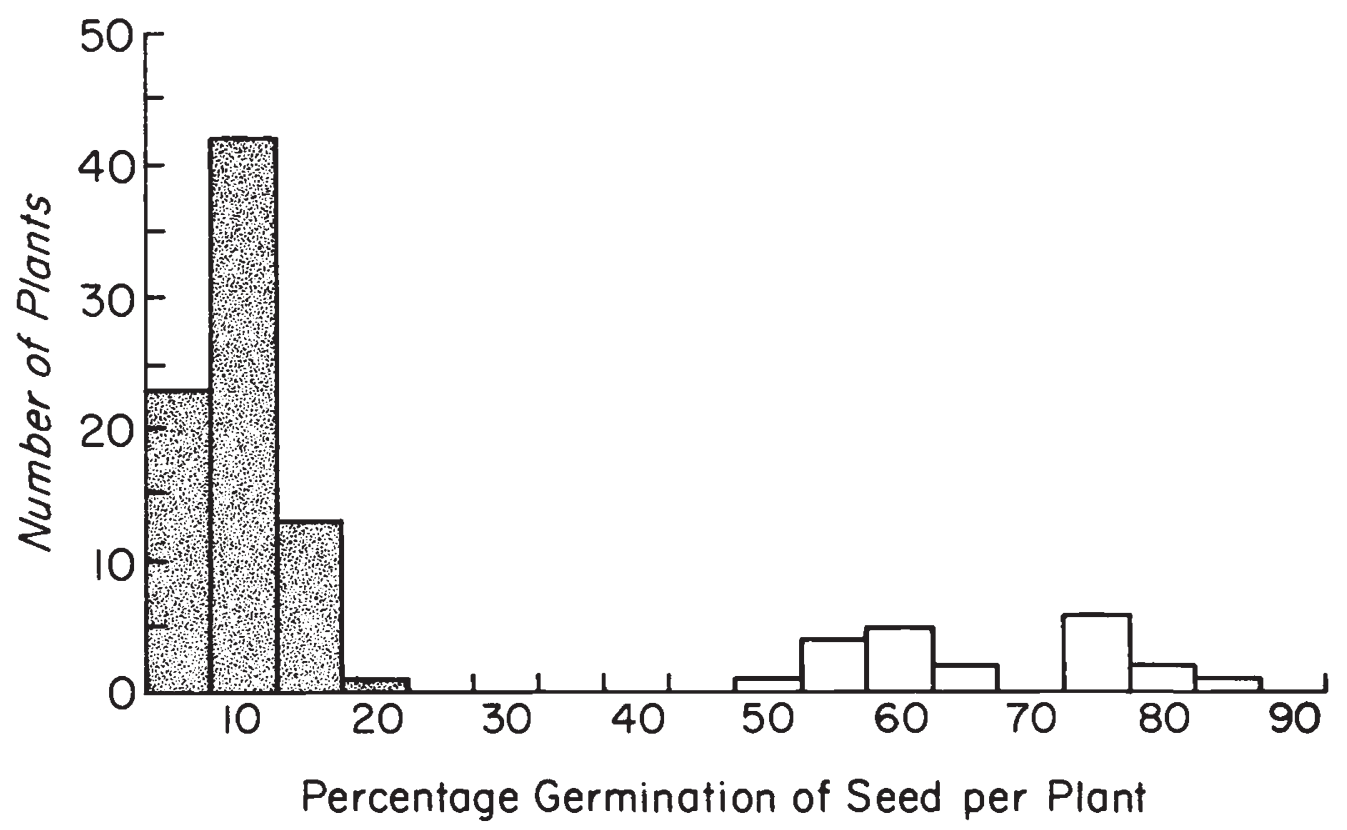

Figure 2 The range and frequency of germination percentages shown by the seed $\left(\mathrm{F}_{2}^{s} \mathrm{~F}_{3}^{e}\right)$ and $\mathrm{F}_{2}^{e}$ plants. Plants with germination percentage less than 40 percent were considered dormant genotypes; those above 40 percent were considered non-dormant genotypes.

ploughing; yet because of the large number of seeds in the seed bank, some at least will produce non-dormant seed in those years when autumnal ploughing is late or does not occur, and there will be an autumnal "flush" which will reproduce. Spring ploughing will have a similar effect upon those individuals which germinate in the spring, but will also tend to bring up to the surface buried seed which will germinate later. As it requires only one good year in 11 to maintain the seed population (Edwards, 1980) and with the prevalence of mixed agricultural practice in those areas where $S$. arvensis occurs, it is unlikely that a population would be removed by cultivation alone.

Thus, in $S$. arvensis we find a genetic system that controls dormancy not only by imparting a range of dormancy types, but also of a nature (the element of maternal control) that protects from over-reaction to selection by temporary environmental perturbations, and appears to be a valuable mechanism in adaptation to agricultural systems.

Acknowledgments The authors would like to thank Professor J. L. Harper, Professor F. A. Bazzaz, Dr P. J. Murphy and an anonymous reviewer for their comments and advice, and $C$. Garbutt for her help with the crosses. This work was supported by a Science Research Council grant to K. Garbutt.

\section{REFERENCES}

CHARLESWORTH, B. 1974. Selection in populations with overlapping generation. VI. Rates of change of gene frequency and population growth rates. Theoretical Population Bio$\log y, 6,108-133$.

COHEN, D. 1966. Optimising reproduction in a randomly varying environment. Journal of Theoretical Biology, 12, 119129.

EDWARDS, M. M. 1968a. Dormancy in seeds of Charlock (Sinapis arvensis). 1. Developmental anatomy of the seed. Journal of Experimental Botany, 19, 575-582.

EDWARDS, M. M. 1968 b. Dormancy in seeds of Charlock (Sinapis arvensis). 2. The influence of the seed coat. Journal of Experimental Botany, 19, 583-600.

EDWARDS, M. M. 1968c. Dormancy in seed of Charlock (Sinapis arvensis). Occurrence and mode of action of an inhibitor associated with dormancy. Journal of Experimental Botany, 19, 601-610.

EDWARDS, M. M. 1969. Dormancy in seeds of Charlock (Sinapis arvensis). 4. Interrelationships of growth, oxygen supply and concentration of inhibitor. Journal of Experimental Botany, 20, 876-894.

EDWARDS, M. M. 1976. Dormancy in seeds of Charlock (Sinapsis arvensis). Early effects of Gibberellic acid on the synthesis of amino acids and proteins. Plant Physiology, 58, 626-630.

EDWARDS, MIRIAM. 1980. Aspects of the population ecology of Charlock. Journal of Applied Ecology, 17, 151-172.

FRANKLAND, B. 1976. Phytochrome control of seed germination in relation to the light environment. Proceedings of the 22nd Easter School in Agricultural Science, University of Nottingham, Smith, H. (ed.) Butterworths, London, pp. 169-188. 
GUENTHER, E. AND BORRISS, H. 1975. The genetic control of germination of Antirrhinum seeds. 2. The genetic basis of influence of Gibberellic acid on the germination of Antirrhinum seeds. Biologisches Zentralblatt, 94, 45-61.

HARPER, J. L. AND McNAUGHTON, 1. H. 1960. The inheritance of dormancy in inter- and intraspecific hybrids of Papaver. Heredity, 15, 315-320.

HILU, K. W. AND DE WET, J. M. J. 1980. Effect of artificial selection on grain dormancy in Eleusine (Gramineae). Systematic Botany, 5, 54-60.

HOMING, J. A. 1930. Nucleus and Plasma in the heredity of the need of light for germination in Nicotiana seeds. Genetica, 12, 441-468.

JAIN, S. K. 1982. Variation and adaptive role of seed dormancy in some annual grassland species. Botanical Gazzette, 143, 101- 106.

JANA, S., ARCHARYA, S. N. AND NA YLOR, J. M. 1979. Dormancy studies in seed of Avena fatua. 10. On the inheritance of termination behaviour. Canadian Journal of Botany, 56, 1663-1667.

NAYLOR, J. M. AND FEDEC, P. 1978. Dormancy studies in seed of Avena fatua. 8. Genetic diversity affecting response to temperature. Canadian Journal of Botany, 54, 2224-2229.

NAYLOR, J. M. AND JANA, S. 1976. Genetic adaptation for seed dormancy in Avena fatua. Canadian Journal of Botany, 54 306-312.
NEW, J. K. 1958. A population study of Spergula arvensis. Part 1. Two clines and their significance. Annals of Botany, 22, 457-477.

NEW, J. K. 1959. A population study of Spergula arvensi. Part 2. Genetics and breeding behavior. Annals of Botany, 23, 23-33.

NEW, J. K. 1961. Biological fluora of the British Isles. No 76 Spergula arvensis. Journal of Ecology, 49, 205-215.

ROHLF, F. J. AND SOKAL, R. R. 1981. Satistical Tables. W. M. Freeman and Co. Oxford, $219 \mathrm{pp}$.

SAWHNEY, R. AND NAYLOR, J. M. 1979. Dormancy studies in seed of Avena fatua. 9. Demonstration of genetic variability affecting the response to temperature during seed development. Canadian Journal of Botany, 57, 59-63.

TEMPleton, A. R. AND LEVIN, D. A. 1979. The evolutionary consequences of seed pools. American Naturalist, 114, 233249.

WITCOMBE, J. R. 1971. Genetic analysis of dormancy, germination and growth in three Cruciferous species. Ph.D. Thesis, University of Nottingham.

WITCOMBE, J. R., HILLMAN, J. AND WHITTINGTON, W. J. 1969. Growth inhibitor in the seed coat of Charlock. Nature, 222, 1200.

WITCOMBE, J. R. AND WhitTINGTON, w. J. 1972. The effects of selection for reduced dormancy in Charlock (Sinapis arvensis). Heredity, 29, 37-49. 